\title{
Toxicity of citrate-capped AuNPs: an in vitro and in vivo assessment
}

\author{
Stefania Sabella $\cdot$ Virgilio Brunetti · Giuseppe Vecchio • \\ Antonio Galeone • Gabriele Maiorano • \\ Roberto Cingolani • Pier Paolo Pompa
}

Received: 19 July 2011/Accepted: 21 September 2011/Published online: 8 October 2011

(C) Springer Science+Business Media B.V. 2011

\begin{abstract}
In this study, we show that $15 \mathrm{~nm}$ citratecapped AuNPs exert a remarkable toxicity in living systems. The assessment was performed by using well-characterized AuNPs, the combination of in vitro and in vivo models (namely two different cell lines and Drosophila melanogaster), exposure to low dosages of nanoparticles (in the sub-nanomolar concentration range), along with the application of several biological assays to monitor different aspects of the toxic effects, such as viability, genotoxicity, and molecular biomarkers.
\end{abstract}

Keywords Nanotoxicology · Gold nanoparticles · In vitro $\cdot$ In vivo $\cdot$ Environmental, health and safety (EHS)

S. Sabella and V. Brunetti contributed equally to this work.

Electronic supplementary material The online version of this article (doi:10.1007/s11051-011-0590-x) contains supplementary material, which is available to authorized users.

S. Sabella · V. Brunetti - G. Vecchio .

A. Galeone · G. Maiorano · P. P. Pompa ( $\varangle)$

Italian Institute of Technology (IIT), Center

for Bio-Molecular Nanotechnology@UniLe,

Via Barsanti, 73010 Arnesano, Lecce, Italy

e-mail: pierpaolo.pompa@iit.it

R. Cingolani

Italian Institute of Technology, Central Research

Laboratories, Via Morego 30, 16136 Genoa, Italy

\section{Introduction}

Given the increasing commercialization of products containing gold nanoparticles (AuNPs) in recent years (e.g., hair tonics, cosmetics, toothbrushes, conductive ink, lubricating oil, etc.), concerns about their possible impact on human health and environment are strongly emerging. Exposure to AuNPs may come from direct or indirect contact with consumer products, manufacturing processes, and environment. However, due the presumed inertness and biocompatibility of gold (based on macroscale evidences), along with the ancient use of bulk and gold salts as drugs and food additives, AuNPs were long considered as safe. In particular, due to their excellent size-dependent physical properties, AuNPs have been therefore applied in many fields of nanomedicine, including diagnostics (El-Sayed et al. 2005), imaging (Eck et al. 2010), and therapeutics (Gibson et al. 2007; Rosi et al. 2006). Indeed, on the basis of such assumptions, nanoscale gold has been regarded as a potential negative standard for the evaluation of the toxicity of nanomaterials. Nevertheless, publications reporting toxicity of AuNPs are recently increasing (Chompoosor et al. 2010; Jan et al. 2008; Li et al. 2008, 2010; Maiorano et al. 2010; Massich et al. 2010; Pan et al. 2009; Patra et al. 2007; Pernodet et al. 2006; Schaeublin et al. 2011), in contrast with other papers that contrarily report about their safety (Brandenberger et al. 2010; Connor et al. 2005; Gannon et al. 2008; Khan et al. 2007; Shukla et al. 2005). Also, the gap in such discrepancy narrows 
when analyzing the arsenal of the different batches of AuNPs used in toxicology tests, the very different experimental conditions, and the numerous cell lines/ animal models employed, rendering the biological outcomes questionable in some cases or, at least, not always comparable. Notably, in this regard, we have recently demonstrated that the surface coating may play a crucial role in determining the specific impact of AuNPs on cells (Sabella et al. 2011). In particular, by analyzing published data, it was observed that naked AuNPs (usually surrounded by weakly bound molecules, such as citrate-capped AuNPs) are significantly toxic both in vitro and in vivo, while proper surface coating (such as protein- or polymer-coating) may partially/significantly prevent their toxic effects (although most of the in vivo data indicate toxicity also in this latter case, likely due to a partial/total leaking of the protective layer on the long term) (Sabella et al. 2011). In any case, also other experimental variables may affect the biological outcomes, generally causing a lack of harmonization among nanotoxicity results. Nowadays, it is well recognized that an in-depth physical/chemical characterization of NPs (leading to an unequivocal definition of size, shape, coating, surface charge, dispersion, purity, etc.) is necessary for obtaining accurate toxicity data. In particular, the NPs characterization should be performed both after the synthetic processes and after incubation with the biological media (Rivera Gil et al. 2010). As a direct consequence, a proper selection of several analytical techniques for the correct metrology assessment (e.g., TEM, SEM, DLS, Z-pot, ICP, EDX, FTIR, etc.) along with use of realistic dosages of AuNPs, appropriate choice of cell/animal models, administration routes, combination of different molecular assays and, possibly, comparison of in vitro results with those obtained by in vivo experiments, are all fundamental conditions for validating results in nanotoxicology (Krug and Wick 2011; OECD 2010).
Taking into account such important issues, in this study we evaluated the toxicity of $15 \mathrm{~nm}$ citratecapped AuNPs, by using (i) metrologically assessed AuNPs, (ii) the combination of in vitro and in vivo models, and (iii) the analysis of several biological assays to monitor different aspects of the toxic effects, such as viability, genotoxicity, and molecular biomarkers. The employed AuNPs had high water stability, purity, and monodispersion (size dispersion $<5 \%$ ). In the in vitro experiments, AuNPs were tested on two different cellular lines (HeLa and U937) in the sub-nanomolar concentration range, whereas, for the in vivo testing, we employed the animal model Drosophila melanogaster. In both cases, experimental results indicate that these AuNPs were significantly toxic, producing important harmful effects, such as cytotoxicity and genotoxicity, along with clear changes of vital parameters of the fruit flies (e.g., life span and fertility decreases).

\section{Results and discussion}

Table 1 reports the characterization data of the assynthesized citrate-capped AuNPs in water and after incubation with the cell culture medium. In particular, TEM analyses revealed that the AuNPs are highly monodispersed, while DLS and z-potential measurements confirmed a narrow size distribution and a good stability also in aqueous solution, thanks to citrate capping. On the other side, on incubation with the cell culture medium (RPMI supplemented with serum proteins), we observed an increase of the NPs diameter with a slight decrease of the overall surface charge (no detectable aggregation was found by both techniques). Such changes were elicited by the formation of protein corona (Cedervall et al. 2007; Lundqvist et al. 2008; Maiorano et al. 2010).

Table 1 Chemical-physical assessment of $15 \mathrm{~nm}$ citrate-capped AuNPs "as-synthesized" in water and on incubation for $24 \mathrm{~h}$ with the cell culture medium (RPMI) supplemented with protein source (10\% FBS)

\begin{tabular}{lllr}
\hline & TEM & DLS & Z-pot \\
\hline As-synthesized & $D: 15.2 \pm 0.2 \mathrm{~nm}$ & $D_{\mathrm{H}}: 17.7 \pm 2.2 \mathrm{~nm}$ & $-38.3 \pm 5.2 \mathrm{mV}$ \\
In cell culture medium & $D: 22.1 \pm 1.1 \mathrm{~nm}$ & $D_{\mathrm{H}}: 39.7 \pm 3.5 \mathrm{~nm}$ & $-23.3 \pm 6.1 \mathrm{mV}$
\end{tabular}

DLS values of the protein corona related to the different time points used in the cellular experiments $(24,48,72$, and $96 \mathrm{~h})$ were also measured, finding that the corona maintains a stable value around $40 \mathrm{~nm}$ 
For the in vitro experiments, HeLa and U937 cells were cultured in RPMI supplemented with $10 \%$ of bovine fetal serum (FBS), in the presence of increasing dosage of $15 \mathrm{~nm}$ citrate-capped AuNPs. To investigate the occurrence of any adverse biological effects induced by the treatment with the AuNPs, we applied water-soluble tetrazolium salt (WST-8) test to monitor cellular viability, di-chloro-fluorescein (DCF) assay to quantify reactive oxygen species (ROS) generation and lactate dehydrogenase (LDH) leakage assay to determine possible membrane damage. The viability assay indicated a significant cytotoxicity of AuNPs in both cell lines that was time- and concentrationdependent (Fig. 1a, b). At the highest concentration value $(500 \mathrm{pM})$, we observed a viability reduction of about $30-40 \%$ with respect to the control. The supernatant ( $\mathrm{SN}$ ) was found to induce no detectable effects in both cell lines, thus excluding possible contributions of salts, reaction precursors, or contaminants to the observed toxicity. The LDH assay supported the toxicity findings, indicating significant membrane damage in cells on interaction with citratecapped AuNPs (Fig. 1c, d). To further investigate the mechanism of toxicity, we analyzed the ROS levels in the two cell lines (Fig. 1e, f). Consistent with the previous experiments, we found a concentration- and time-dependent increase of the ROS in both cases. At the highest concentration (500 pM), a significant ROS generation was found, especially in the HeLa cells. The different levels of ROS between the two cell lines may be ascribed to their different expression level of antioxidant enzymes, such as catalase and SODs. In particular, U937 cells are typically characterized by high levels of catalase activity, as compared to other human cell lines, with a consequent higher resistance to oxidative stress (Lledías and Hansberg 1999; Yamamoto et al. 2008). At any rate, such high level of ROS may account for membrane and DNA damage as well as cellular death (see also below).

Citrate-capped AuNPs uptake and cellular distribution were assessed in HeLa and U937 cells by confocal microscopy and ICP. In the first experiments, by exploiting the intrinsic two-photon luminescence of nanoscale gold (Farrer et al. 2005; Yelin et al. 2003), AuNPs were detected without using labeling procedures with fluorescent probes. Such label-free cellular tracking of AuNPs prevents possible imaging artifacts due to the release of free dye in cells. Representative confocal images of the two lines are shown in Fig. 2a, b. In both cases, we found that AuNPs (red spots) were actively internalized by cells in a quite similar manner, being predominantly localized into the cytoplasm and distributed in the perinuclear region. However, quantitative analyses by ICP-AES revealed a different uptake of the AuNPs by the two cellular types. The overall amount of internalized gold was significantly higher in the HeLa cells than in the monocyte line. After $48 \mathrm{~h}$ of treatment with $500 \mathrm{pM}$ AuNPs, we detected $17.21 \pm 0.72 \mathrm{pM}$ of gold for HeLa and $1.29 \pm 0.03 \mathrm{pM}$ for U937 (per cell). The different uptake of NPs can be ascribed to the significantly different cellular volumes of the two investigated lines (especially in terms of cytoplasm) and, in part, also to their diverse uptake efficiency (active mechanisms, different cellular metabolism, kinetics, and so on). In any case, despite such different internalization of AuNPs (ca. 13-fold), the two cell lines exhibit similar toxicity. This interesting finding clearly deserves further tailored investigations to clarify, among other factors, a possible role of the "intracellular density" of internalized NPs in triggering NPs uptake and overall toxicity (interestingly, the volume ratio between HeLa and U937 is also ca. 13) (Downey et al. 1990; Zhao et al. 2008), beyond the bare concept of NPs concentration in the culture medium and total amount of uptaken nanomaterials.

To monitor the possible adverse effects of citratecapped AuNPs in terms of DNA damage, we performed the terminal deoxynucleotidyl transferase dUTP nick end labeling (TUNEL) assay on both cell lines, on incubation with increasing concentration of NPs (48 and $96 \mathrm{~h}$ incubation times). Importantly, we observed significant DNA fragmentation following exposure to citrate-capped AuNPs (Fig. 2c, d). Consistent with the previous experiments, DNA damage was found to be time- and dose-dependent. In particular, monocytes were observed to be particularly sensitive to the presence of AuNPs in terms of genetic damage. In both cases, however, a clear indication of strong nuclear damage was evident, although we observed that $15 \mathrm{~nm}$ citrate-capped AuNPs do not directly interact with cell nuclei. The available evidence suggests a ROS-mediated damaging effect of NPs on cellular DNA. As a final step, we investigated the toxicity effects of the NPs in vitro by AnnexinV/PI assay to detect the possible formation of apoptotic/necrotic cells. We found that the exposure of both cell lines to increasing concentration of AuNPs 


\section{HeLa}
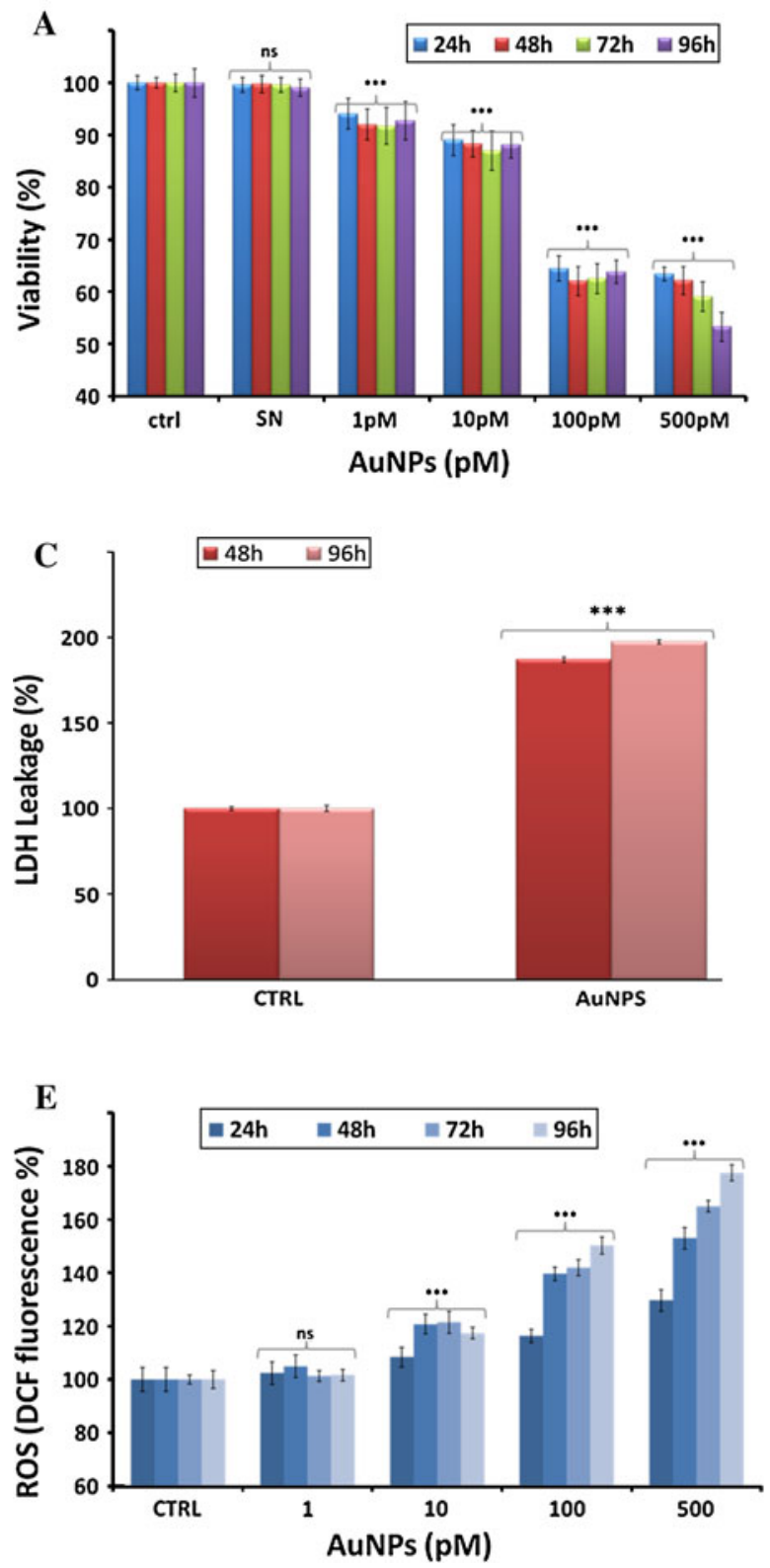

Fig. 1 a, b WST-8 proliferation assay in the two cellular lines (HeLa and U937) after citrate-capped AuNPs exposure. CTRL represents the negative control and $\mathrm{SN}$ the supernatant; values are means $\pm \mathrm{SD}$. $* * * p \leq 0.001$ compared with control $(n=8)$. Importantly, before analyses, possible interference phenomena between AuNPs and both WST-8 reagent and product (formazan) were evaluated (see "Experimental"), finding out no significant interferences in the AuNPs concentration range used

\section{U937}
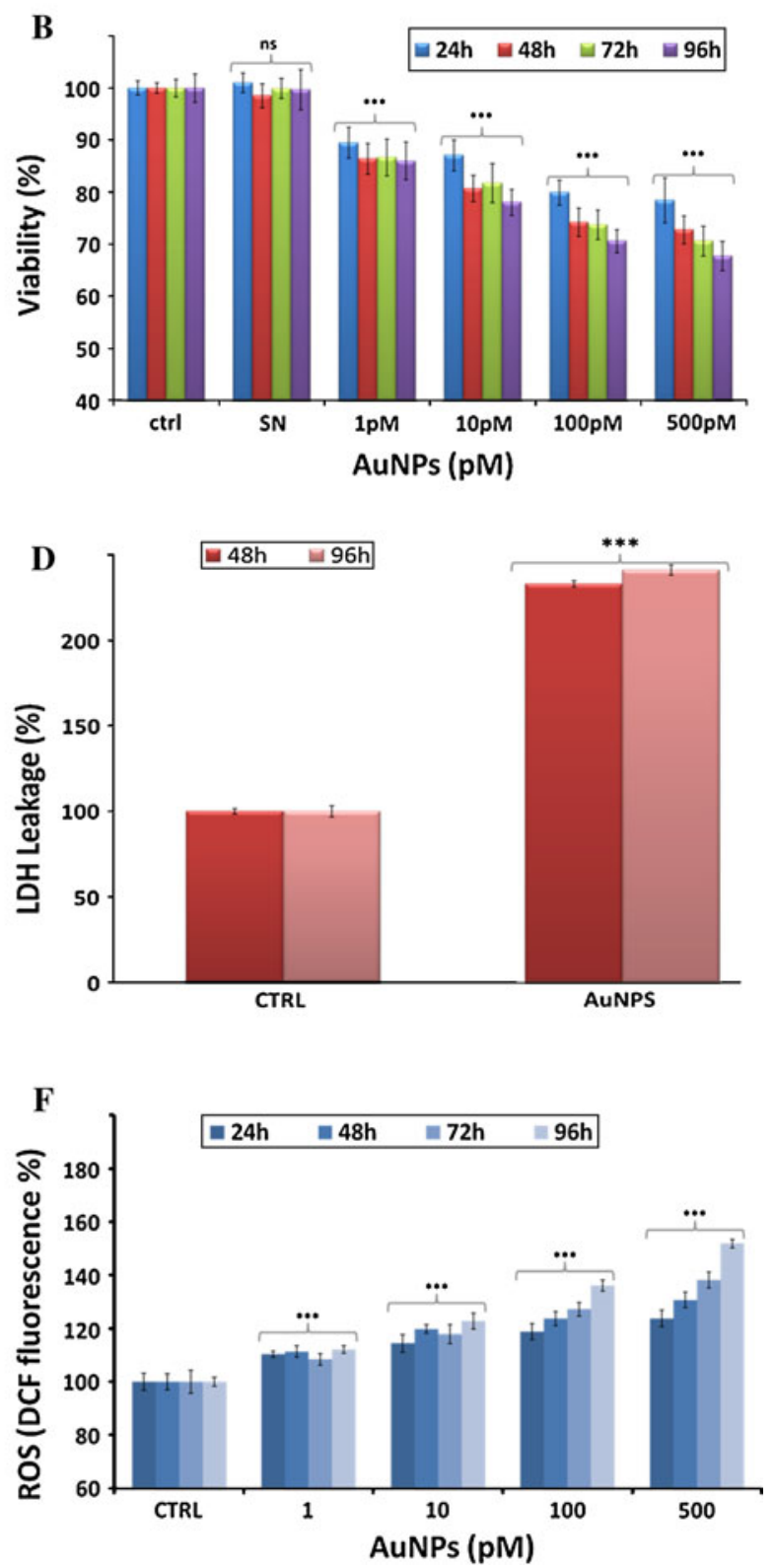

here (data not shown). c, d LDH assay performed on HeLa and U937 cells cultured for 48 and $96 \mathrm{~h}$ in the presence of $15 \mathrm{~nm}$ AuNPs (500 pM). Data are expressed in percentage with respect to the negative controls (indicated in the graphs as CTRL); values are means $\pm \mathrm{SD}$. $* * * p \leq 0.001$ compared with control $(n=8)$. e, f ROS quantification after cellular treatment with 500 pM AuNPs; values are means \pm SD. $* * * p \leq 0.001$ compared with control $(n=8)$ 


\section{HeLa}

A

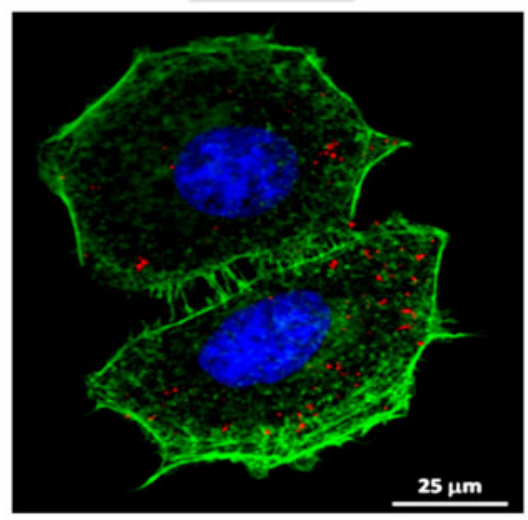

C
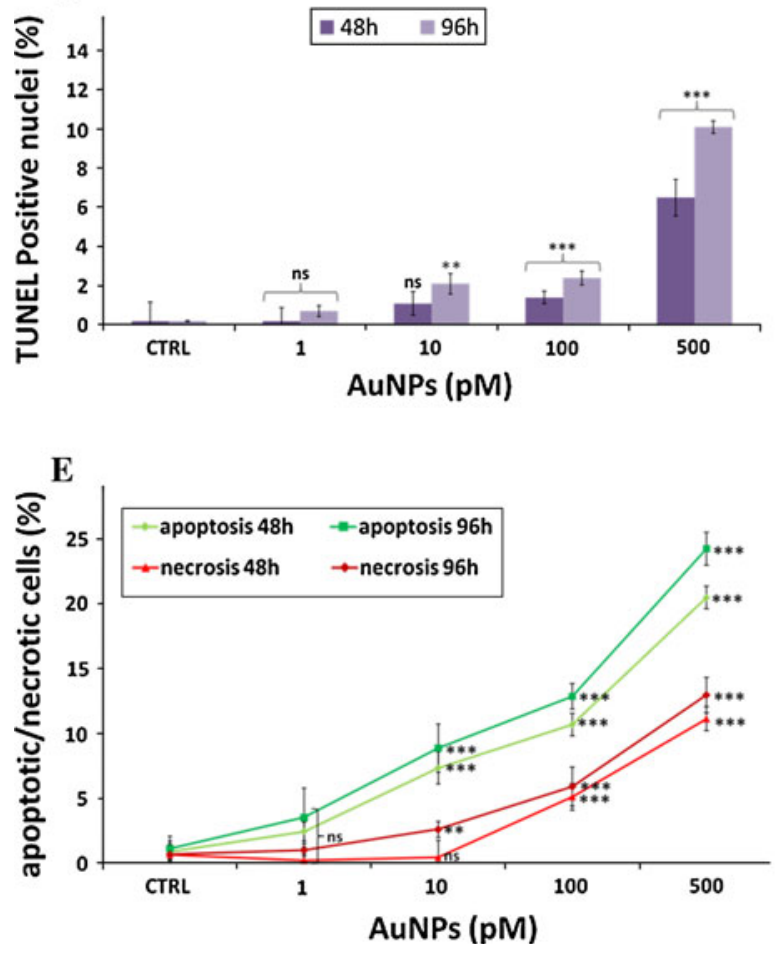

Fig. 2 a, b Representative confocal images of citrate-capped AuNPs uptake by HeLa and U937 cells. AuNPs (perinuclear spots) were detected by two-photon confocal microscopy, while nuclei were stained by Hoechst 33258 and F-actin was labeled by phalloidotoxin conjugated with AlexaFluor488; c, d HeLa and U937 DNA damage as probed with the TUNEL assay. Cells were exposed to $500 \mathrm{pM}$ of AuNPs for $48 \mathrm{~h}$. Cells containing DNA strand nicks were detected by red fluorescence, whereas nuclei were stained with Hoechst 33342 (blue); exposures to
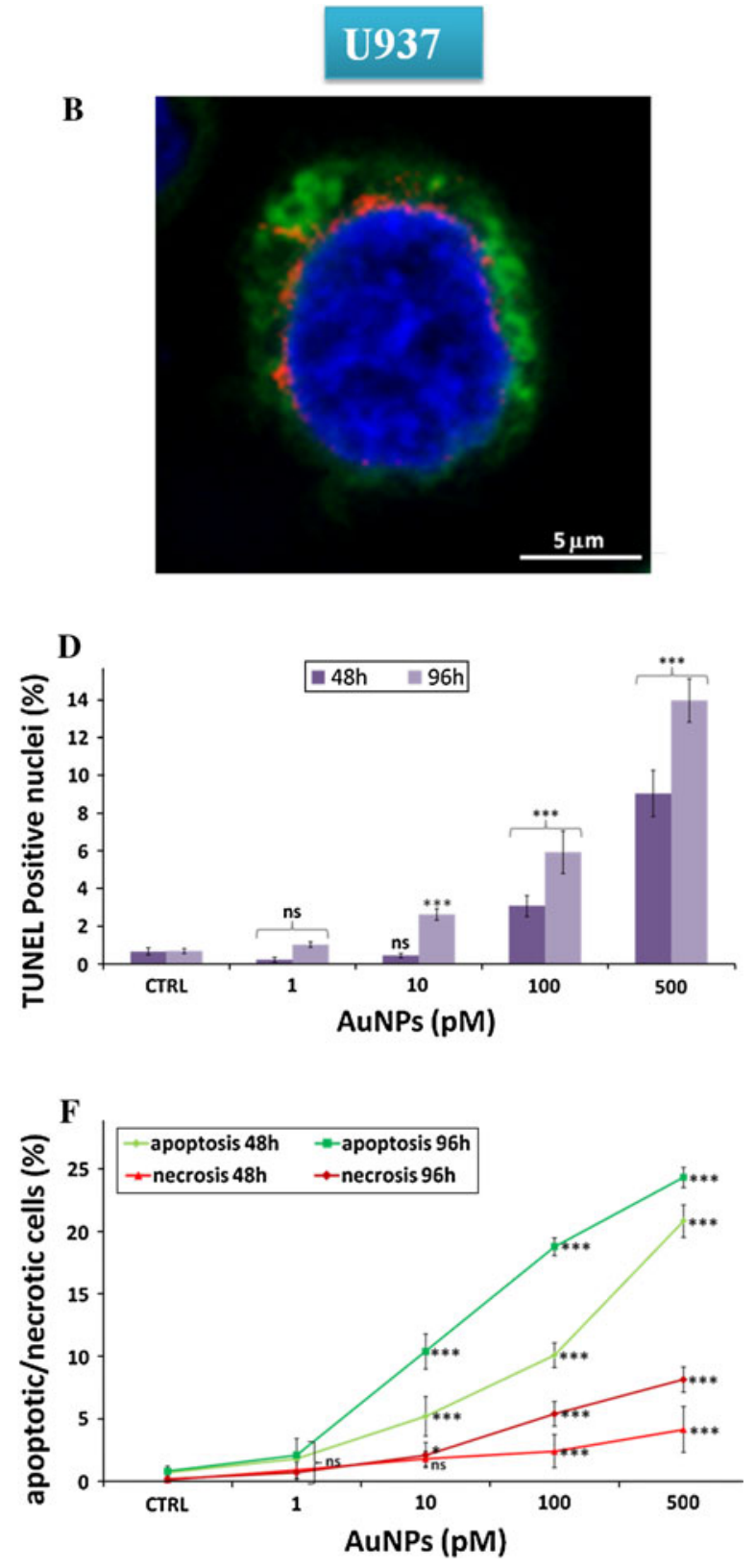

different concentrations were compared with cells with no NPs treatments (CTRL). Values are means \pm SD. ${ }^{*} p \leq 0.05$, $* * p \leq 0.01, * * * p \leq 0.001$ compared with control $(n=5)$; values are non-significant for $p$ value $>0.05(\mathrm{~ns})$. e, $\mathbf{f}$ AnnexinV/ PI assay for monitoring apoptosis/necrosis by confocal microscopy. Cells were exposed to $500 \mathrm{pM}$ of AuNPs for 48 and $96 \mathrm{~h}$ of incubation. Values are means $\pm \mathrm{SD}$. ${ }^{*} p \leq 0.05, * * p \leq 0.01$, $* * * p \leq 0.001$ compared with control $(n=8)$; values are nonsignificant (ns) for $p>0.05$ 
triggered both apoptotic and necrotic processes (Fig. 2e, f). In particular, we observed a remarkable percentage of apoptotic cells at the highest NPs concentrations $(500 \mathrm{pM})$ with a lower but significant occurrence of necrotic events (especially in HeLa cells). This finding is consistent with the previous experiments that highlighted significant DNA and membrane damage as well as high ROS levels.

Overall, our in vitro data indicate that citratecapped AuNPs are highly toxic to cells. Such results are in good agreement with a recent work revealing dramatic changes in the genes expression profile of the whole genome in HeLa cells on treatment with citrate-capped AuNPs (Massich et al. 2010). Although the genesis and molecular mechanisms of toxicity are not yet completely clarified, AuNPs seem to directly or indirectly promote DNA and membrane damage in the cells (as also evidenced by ROS generation and as reported by other groups) (Chompoosor et al. 2010; Li et al. 2008, 2010). In addition, the indirect activation of molecules mediating signaling processes in the medium (Bhabra et al. 2009) leading to DNA damage from a distance, as well as possible biomolecules/AuNPs surface interactions (with consequent unfolding/depletion of proteins and DNA) (Deng et al. 2011) and the intracellular release of metal ions by internalized particles may represent further toxicity mechanisms that still require extensive studies.

To corroborate the in vitro toxicity data of citratecapped AuNPs, we performed additional in vivo investigations. We selected, as animal model, the fruit fly D. melanogaster. Drosophila is an excellent model for toxicology (Jennings 2011; Bhargav et al. 2008) and genetic studies of human diseases (Botas 2007; Lieschke and Currie 2007), and has many advantages, such as the short life cycle, high genes homology with higher animals (also human) and availability of a complete genetic database. Furthermore, fruit flies have been recently used to study the toxicity of some chemicals (Bhargav et al. 2008) and also of nanoparticles (Pompa et al. 2011a, b; Ahamed et al. 2010; Liu et al. 2009). Drosophila is indeed particularly suitable for massive screening of nanomaterials (i.e., in HTSlike approaches) thanks to the limited ethical problems and costs with respect to mouse, while representing a much better model system with respect to in vitro cell cultures.

Flies were fed with food containing two dosages of citrate-capped AuNPs ( 3 and $27 \mu \mathrm{g} / \mathrm{g}$ per day) and SN. The vital parameters lifespan and fertility of nurtured male and female Drosophila flies were monitored over their entire life cycle. As reported in Fig. 3, clear adverse effects were found in treated organisms, namely a strong reduction of their lifespan and fertility as compared to control flies. The lack of detectable effects of SN-treated food excludes possible toxic contributions related to the presence of impurities and/ or other components present in the NPs suspension. Considering that the average lifespan $\left(\tau_{50}\right)$ of untreated flies (control and SN curves) was found to be approximately 82 days (Fig. 3a), we observed a shortening of about 24 and $41 \%$ in the flies treated with the two dosages of AuNPs ( $\tau_{50}$ of 62 and 48 days for 3 and $27 \mu \mathrm{g} / \mathrm{g}$, respectively). Such effect may be considered as a clear indication of in vivo toxicity caused by ingestion of AuNPs. In addition, we observed that the reproductive performances of Drosophila were strongly compromised, with the fertility reduced of about 30 and $50 \%$ in the two treatments (Fig. 3b). The fertility decrease was similar in male and female organisms, suggesting a generalized not sex-linked toxicity. Also, for these in vivo studies, we confirmed a dose-dependent toxicity of AuNPs.

Molecular assays were also applied in the in vivo experiments to better clarify the mechanisms governing the NPs toxicity. In particular, we assessed the presence of oxidative stress by quantifying ROS levels, unrepaired DNA strand breaks by single cell gel electrophoresis (or Comet assay), and the variation of the expression levels of genes involved in stress response and DNA damage by real-time qPCR. For such experiments, we used organisms fed with normal food, SN, and AuNPs-treated food (we selected the lower dosage of AuNPs used in the previous experiments, namely $3 \mu \mathrm{g} / \mathrm{g}$ ). Figure $4 \mathrm{a}$ indicates that, whereas ROS level remained almost unperturbed in $\mathrm{SN}$-fed flies, an increase of about $30 \%$ of reactive species was found in the animals treated with food containing AuNPs. Interestingly, this is consistent with the in vitro data on HeLa and U937 cells. Moreover, the remarkable genotoxicity found in the in vitro studies in both cells lines (Fig. 2c, d) led us to 

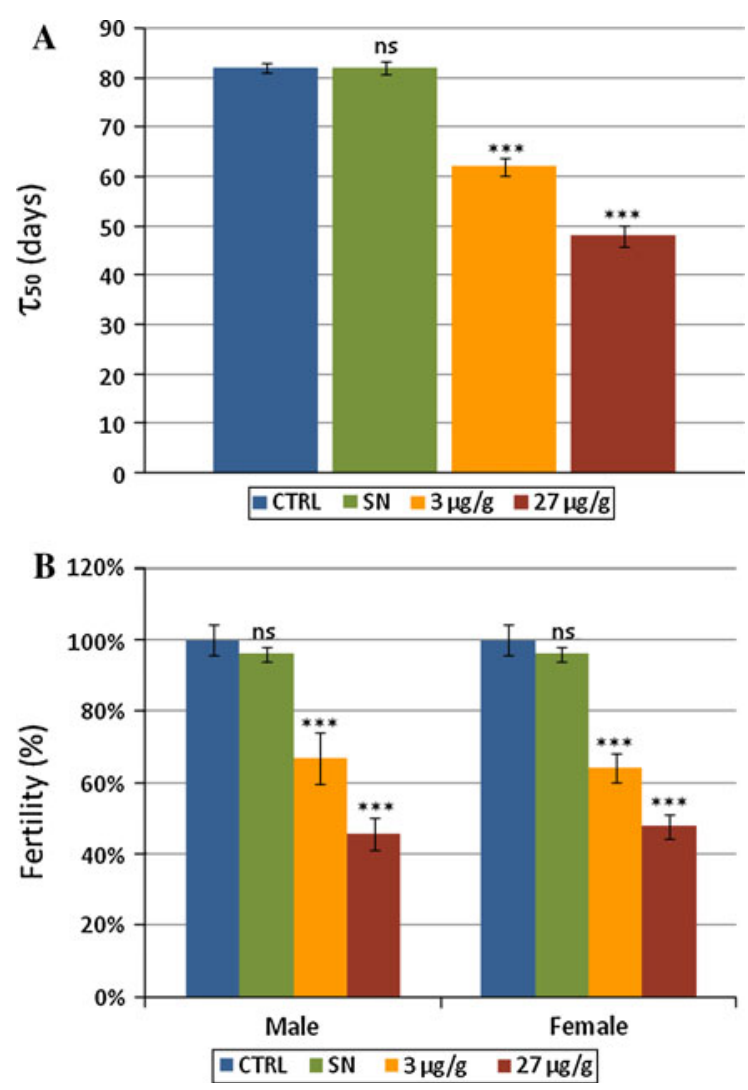

Fig. 3 a Average lifespan $\left(\tau_{50}\right)$ of treated Drosophila. Histograms represent the $\tau_{50}$ values of flies exposed to normal food (CTRL), SN-treated food, and two dosages of citrate-capped AuNPs-treated food ( 3 and $27 \mu \mathrm{g} / \mathrm{g}$ ), respectively. The median survival for CTRL and SN was 82 days, while AuNPs-treated flies was 62 and 48 days. The survival distributions were evaluated by non-parametric log-rank (Mantel-Cox) test, giving $p<0.001$ (for both AuNP treatments with respect to the CTRL; $\chi^{2}=42.69$, $\left.\mathrm{df}=1\right)$, and $p>0.05$ (SN with respect to CTRL; $\chi^{2}=0.08985, \mathrm{df}=1$ ), while the quantification of the $\tau_{50}$ values were assessed by one-way ANOVA (ns non-significant; $* * * p$ value $<0.001)$. b Male and female fertility tests. First and second histograms represent fertility of flies nurtured with CTRL and SN-treated food. Third and fourth are referred to two treatments with AuNPs. Experimental points represent the average from 10 independent experiments and the error bars indicate the standard deviation ( $n s$ non-significant; $* * * p$ value $<0.001)$

investigate also in vivo the possible role of the ingested NPs in inducing DNA damage on the circulating hemocytes of Drosophila. To this aim, the Comet assay is particularly appropriate as it allows for rapid, simple, and sensitive measurement of DNA single-strand breaks and alkali labile sites (Singh et al. 1988). Notably, apart from the current interest in the application of Comet assay in the regulatory genotoxicological tests, many papers have recently demonstrated the advantages of using such technique in the genotoxicity study of diverse nanoparticles (Lin et al. 2006; Warheit 2008; Barnes et al. 2008). We performed such test on the circulating hemocytes since they are highly sensitive to genotoxic agents and are widely recognized as one of the most reliable model system to detect DNA damage in invertebrates for environmental monitoring (Carmona et al. 2011). Figure $4 b$ reports a representative image of the migration of DNA fragments, resulting in the typical shape of a "Comet" that indicates the presence of DNA damage. In particular, we quantified that, in the case of citrate-capped AuNPs treatment, the percentage of positive nuclei was $17.1 \pm 2.9 \%$, whereas the value of the control was as low as $3.7 \pm 1.4 \%$. Importantly, such data strongly evidence the NPsinduced DNA damage in vivo, further corroborating our previous genotoxicity findings in Drosophila based on TUNEL assay (Pompa et al. 2011b). Finally, we measured the levels of $h s p 70$ and $p 53$ genes by means of real-time qPCR. Specifically, hsp70 is a protein involved in the stress response and is part of the heat shock proteins family (Hsps). The upregulation of Hsps is important since they counteract proteotoxic effects and play various roles in cells including chaperoning proteins during synthesis, folding, assembly, and degradation. The heat shock response is induced in a protective way as a consequence of non-specific mechanisms of toxicity, involving generation of abnormal proteins along with alteration of cellular functions. Moreover, the expression of Hsps is strictly related to increased ROS generation (Singh et al. 2009). On the other hand, P53 is a protein playing a key role in the cell-cycle regulation as well as recognition of DNA damage. As shown in Fig. 4c, hsp 70 was largely over-expressed in the treated flies (6-fold higher than the control), strongly supporting the finding of a significant and generalized toxicity of AuNPs. Interestingly, the expression of $h s p 70$ is known to be negatively correlated to the organism lifespan (in agreement with our data), representing a predictive indication of Drosophila survival (Yang and Tower 2009). Moreover, the over-expression of p53 (about 3-fold compared to the control) indicates the presence of genomic perturbation. In fact, P53 is a critical component of the cellular mechanisms that respond to genotoxic 

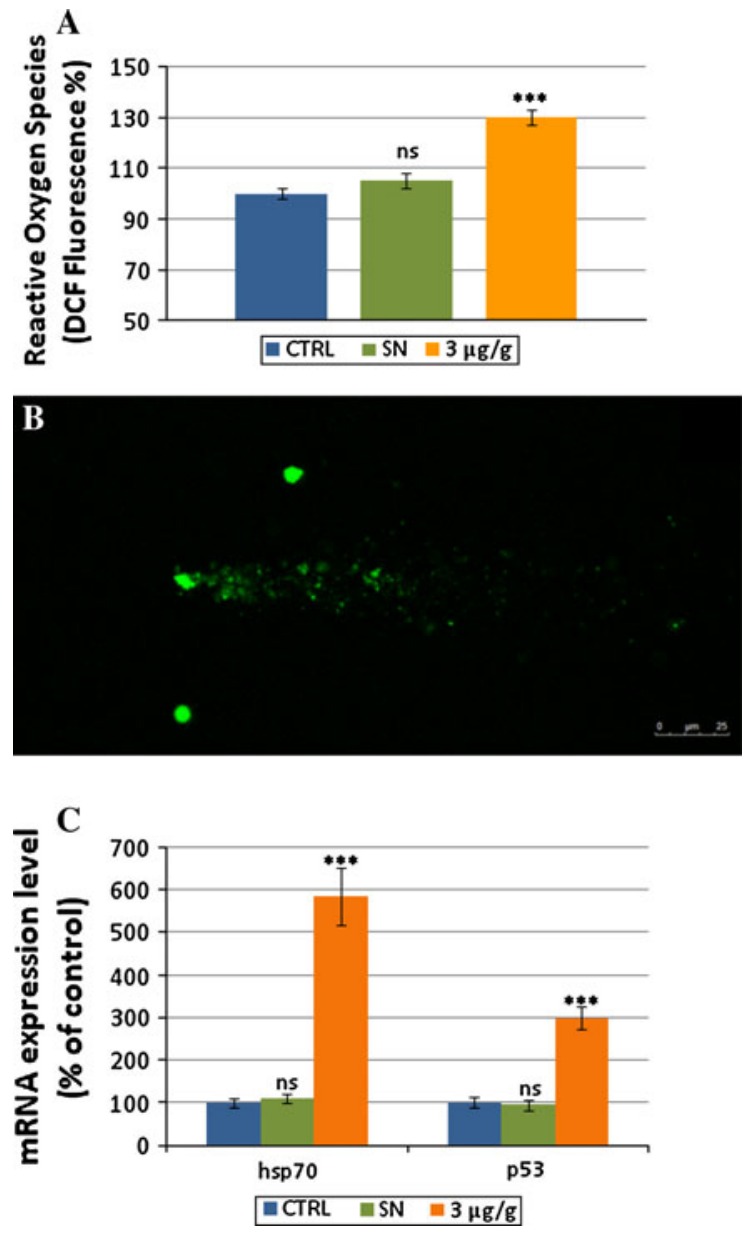

Fig. 4 a ROS measurement by DCF assay in flies nurtured for 25 days with $3 \mu \mathrm{g} / \mathrm{g}$ per day of citrate-capped AuNPs compared to control (CTRL) and supernatant $(\mathrm{SN})$ treated samples. Data are reported as relative fluorescence intensity normalized to the control. Values are means $\pm \mathrm{SD}(n=5)$. Data were validated by one-way ANOVA ( $n s$ not significant; $* * * p$ value $<0.001$ ); b representative confocal microscopy image of Comet assay performed on Drosophila hemocytes treated with the same dosage of $15 \mathrm{~nm}$ AuNPs. c mRNA expression level analyzed by RT-qPCR of Drosophila third instar larvae treated with $3 \mu \mathrm{g} / \mathrm{g}$ of AuNPs compared to control samples (CTRL) and supernatant $(\mathrm{SN})$ treated samples. Values are means $\pm \mathrm{SD}(n=5)$. RTqPCR results were analyzed by two-way ANOVA, and all gene expression was compared to the control by Bonferroni post-test ( $n s$ not significant; $* * * p$ value $<0.001$ )

stresses, like DNA damage and hypoxia, to maintain the genomic integrity, by arresting cell-cycle progression and/or by inducing apoptosis (Zylicz et al. 2001; Somasundaram 2000). Overall, the in vivo data revealed clear adverse effects of AuNPs in Drosoph$i l a$, on ingestion of food containing realistic dosages of AuNPs, with strong reduction of lifespan and reproductive performance, and with the significant presence of clear molecular indicators of toxicity.

\section{Conclusions}

In conclusion, the use of well-characterized AuNPs, of a wide range of toxicity assays, along with the in vitro/ in vivo validation of the toxicity data, provide convincing evidence of the toxic effects of $15 \mathrm{~nm}$ citrate-capped AuNPs. Such findings corroborate recent literature data and have important implications in several fields, including nanomedicine, risk assessment, and regulatory approval for some commercial products. In this respect, further studies are required to establish suitable surface engineering procedures to render AuNPs fully biocompatible, while preserving their peculiar size-dependent properties, which are very promising for several biomedical applications.

\section{Experimental}

Synthesis and physical/chemical characterization of AuNPs

$15 \mathrm{~nm}$ citrate-capped AuNPs were obtained following the Turkevich-Frens method (Frens 1973; Turkevich et al. 1951). The procedure involves the addition of $2.8 \mathrm{~mL}$ of $1 \%$ aqueous solution of sodium citrate (Sigma-Aldrich) to a boiling solution containing $0.25 \mathrm{mM} \mathrm{HAuCl}_{4}$ (Sigma-Aldrich), while stirring. When the classical red color appeared, solution was slowly cooled down. After centrifugation at 16,000g, the NPs pellets were suspended in $150 \mathrm{~mL}$ of ultrapure water. Before their use, AuNPs were filtered using a $0.22 \mu \mathrm{m}$ syringe filters under sterile environment. TEM images were collected casting 300 mesh carboncoated copper grid with a drop of NPs suspension and vacuum dried, by using a JEOL Jem 1011 transmission electron microscope with an accelerating voltage of $100 \mathrm{kV}$. AuNPs concentration was determined by using the molar extinction coefficient measured at the wavelength of their plasmon peak (Lee et al. 2006). Characterizations of NPs in solution were performed by dynamic light scattering (DLS) and zeta-potential analyses using a Zetasizer Nano-ZS instrument (Malvern Instruments) equipped with a $4.0 \mathrm{mV} \mathrm{He}-\mathrm{Ne}$ 
$633 \mathrm{~nm}$ laser. The same characterization procedures were employed for studying NP-protein complexes. After incubation of AuNPs with cell culture medium supplemented with the protein source for $24 \mathrm{~h}$, we determined the size of the complexes by DLS. After, centrifugation was performed to isolate NP-protein complexes $(16,000 \mathrm{~g})$ and the pellet was re-suspended in phosphate buffer saline (PBS) (Sigma-Aldrich) for TEM and zeta-potential measurements.

In vitro assays

\section{Cell cultures}

Human cervix carcinoma cells HeLa (Interlab Cell Line Collection IST Genova, Italy, number HTL95023) and human lymphoma cells U937 (ICLC number HTL94002) were cultured in T75 flasks (Sarstedt) in RPMI 1640 (Sigma-Aldrich) supplemented with 10\% $(\mathrm{v} / \mathrm{v})$ fetal bovine serum (Sigma-Aldrich) and $1 \%(\mathrm{v} / \mathrm{v})$ $10,000 \mathrm{U} / \mathrm{mL}$ penicillin and 10,000 U/mL streptomycin (Sigma-Aldrich). Cells were maintained under standard cell culture conditions $\left(5 \% \mathrm{CO}_{2}, 95 \%\right.$ humidity, and $37{ }^{\circ} \mathrm{C}$ in Thermo Scientific incubator) and harvested every 3 days.

\section{WST-8 cytotoxicity assay}

The metabolic activity of HeLa and U937 cells was measured after $24,48,72$, and $96 \mathrm{~h}$ of exposure to $15 \mathrm{~nm}$ AuNPs, utilizing a colorimetric assays based on the detection of highly water-soluble tetrazolium salt WST-8 (2-(2-methoxy-4-nitrophenyl)-3-(4-nitrophenyl)-5-(2,4-disulfophenyl)-2H-tetrazolium, monosodium salt) (Cell Counting Kit-8 Fluka); assays were performed in 96-well microplates (Sarstedt) for each time $(24,48,72$, and $96 \mathrm{~h})$. Cells were seeded in microplates at a density of 5,000 cells/well and cultured for 24 h. $96 \mathrm{~h}$ represents the maximum time in which cell viability is not influenced by deficiency of nutrients. Different amounts of AuNPs dispersed in cell culture medium stock solution were added in the single wells obtaining final AuNPs concentrations of $1,10,100$, and $500 \mathrm{pM}$. A final concentration of $5 \%$ DMSO in the medium was used as positive control for both cell lines; this treatment generated a viability reduction in the range of $80-90 \%$ with respect to the negative control (data not shown in the graphs). The potential cytotoxicity of AuNPs solvent was also evaluated. We centrifuged AuNPs suspension at the maximum concentration investigated $(500 \mathrm{pM})$, and the $\mathrm{SN}$ was thus added to the cell seeded into microplates to characterize its intrinsic cytotoxic potential. Eight replicates were forecasted for each investigated point considering also controls (CTRL, untreated cells) and blanks constituted by the medium only. A $10 \mu \mathrm{L}$ aliquot of WST-8 solution was added to each well. The 96-well microplates were incubated for $3 \mathrm{~h}$ in a humidified atmosphere of $5 \% \mathrm{CO}_{2}$ and $37{ }^{\circ} \mathrm{C}$. Subsequently, the orange WST-8 formazan product was measured by using Fluo Star Optima (BMG LABTECH) microplates reader at a wavelength of $460 \mathrm{~nm}$. Data were collected by Control Software and elaborated with MARS Data Analysis Software (BMG LABTECH). To express the cytotoxicity, the average absorbance of the wells containing cell culture medium without cells was subtracted from the average absorbance of the solvent control, 5\% DMSO, or AuNPs-treated cells. The percentage cell viability was calculated using the following equation: (Absorbance treated $_{\text {/ }}$ Absorbance $\left._{\text {control }}\right) \times 100$.

Following the observations reported by Park and colleagues (Park et al. 2009), possible interference phenomena between AuNPs and both WST-8 reagent and product (formazan) were evaluated. To this scope, two different WST-8 interference tests were performed. The first one was directed to assess if the AuNPs interfere with the WST- 8 reagent in the concentration range used in this study. In a 96-well microplate, either $100 \mu \mathrm{L}$ of cell culture medium or cell culture medium containing AuNPs in all the tested concentrations $(1,10,100$, and $500 \mathrm{pM})$ was added to the wells (without cells). The plate was then placed for $24 \mathrm{~h}$ in a humidified atmosphere $\left(5 \% \mathrm{CO}_{2}\right.$ and $\left.37{ }^{\circ} \mathrm{C}\right)$. Following this incubation period, $10 \mu \mathrm{L}$ of Cell Counting Reagent WST-8 was added to each well, and the plate was incubated for $3 \mathrm{~h}$ in a humidified atmosphere of $5 \% \mathrm{CO}_{2}$ and $37{ }^{\circ} \mathrm{C}$. Absorbance of each well was measured as described above. Data indicated that in this concentration range, no interferences were detected. The second interference test was designed to determine whether AuNPs interfere with the WST-8 formazan reaction product. HeLa cells were seeded in a 96-well microplate at a density of 5,000 cells/well and cultured for $24 \mathrm{~h}$ at $37^{\circ} \mathrm{C}$ in $5 \% \mathrm{CO}_{2}$. The following day, cell culture medium was removed from the cells and replaced by $100 \mu \mathrm{L}$ of fresh cell culture 
medium. Next, $10 \mu \mathrm{L}$ of Cell Counting Reagent WST8 was added to each well. Following an incubation of $3 \mathrm{~h}$ in a humidified atmosphere of $5 \% \mathrm{CO}_{2}$ and $37{ }^{\circ} \mathrm{C}$, the SN was removed from the cells and transferred to new 96-well microplates. Subsequently, absorbance of each well was measured as described above. A $10 \mu \mathrm{L}$ portion of RPMI freshly prepared AuNPs suspension was added to the wells to a final concentration of nanoparticles identical to the previous assays, and the absorbance was determined again. Results indicated that the interference of the WST-8 product was not significant also at the highest AuNPs concentration (500 pM) (data not shown).

\section{LDH leakage assay}

HeLa and U937 cells were seeded in 96-well microplates and treated with $15 \mathrm{~nm}$ citrate-capped AuNPs at a final concentration of $500 \mathrm{pM}$, following the procedures reported for the WST-8 assay. After 48 and $96 \mathrm{~h}$ of cells-NPs interaction, the LDH leakage assay was performed onto microplates by applying the CytoToxONE Homogeneous Membrane Integrity Assay reagent (Promega), following the manufacturer's instructions. LDH released in the extracellular environment was measured with a 10 min coupled enzymatic assay that results in the conversion of resazurin into fluorescent resorufin $(560 \mathrm{Ex} / 590 \mathrm{Em})$ by using Fluo Star Optima (BMG LABTECH) microplates reader. As negative controls, we applied the same assay onto untreated cells. Results were normalized with respect to the negative controls (expressed as $100 \%)$. Positive controls consisted in the treatment of such cells with $0.9 \%$ Triton X-100 that gave leakage values in the range of 700-800\% (data not reported). Data were expressed as mean $\pm \mathrm{SD}$.

\section{DCF-DA assay and ROS quantification}

Oxidative stress of HeLa and U937 cells was determined after 24, 48, 72, and $96 \mathrm{~h}$ of exposure to $15 \mathrm{~nm}$ citrate-capped AuNPs (1, 10, 100, and 500 pM). On the day of the experiments, in a single microplate, after removing the medium, each concentration of AuNPs (8 replicates) was washed with KRH buffer and then incubated with $100 \mu \mathrm{M}$ DCFH-DA (6-Carboxy-2,7dichlorofluorescin diacetate, Sigma) in the loading medium (RPMI $1 \%$ FBS) in $5 \% \mathrm{CO}_{2} / 95 \%$ air at $37{ }^{\circ} \mathrm{C}$ for $30 \mathrm{~min}$. After DCFH-DA was removed, the cells were washed and incubated with KRH buffer. The positive controls were treated with a free radical generator $\left(\mathrm{H}_{2} \mathrm{O}_{2}\right.$ at a concentration of $\left.100 \mu \mathrm{M}\right)$. Positive controls showed an increase of ROS around 190-210\% with respect to the untreated cells (data not shown in the graphs). The fluorescence of the cells from each well was measured and recorded immediately and after $30 \mathrm{~min}$. In the same microplates, the other eight replicates of each treatment were used to monitor in parallel the viability of cells by Calcein AM assay. Cells were washed twice with KRH buffer and Calcein AM was added at a final concentration of $2.5 \mu \mathrm{M}$ in the same buffer. The positive controls were treated with Triton X100 at final concentration of $0.05 \%$. In any case, to avoid any false results, due to the sensitivity of Calcein AM to ROS generation, cell number was monitored by hemocytometer direct counting using Trypan blue exclusion dye. In all experiments, to conform fluorescence values across the microplate, the same gain setting was used. After adding DCF-DA (or Calcein AM) to the samples, the plates were read by using Fluo Star Optima (BMG LABTECH) microplates reader for quantification of the fluorescence intensity (FI) (485 nm excitation and $520 \mathrm{~nm}$ emission). The ROS generation (DCF-DA assay) was calculated as the increase in FI per well by the formula $\left(\mathrm{FI}_{\mathrm{t} 30}-\mathrm{FI}_{\mathrm{t} 0}\right) / \mathrm{FI}_{\mathrm{t} 0}$, where $\mathrm{FI}_{\mathrm{t} 30}$ is the fluorescence at time $30 \mathrm{~min}$ and $\mathrm{FI}_{\mathrm{t} 0}$ is the fluorescence at time 0 min. ROS generation of single treatment was normalized considering the eventual viability reduction related to the treatments with AuNPs and expressed as percentage increase of FI relative to the controls $\pm \mathrm{SD}$, by using the formula $\left(\mathrm{FI}_{\text {treated }} / \mathrm{FI}_{\text {control }}\right) \times 100$. The reproducibility of the results was guaranteed by performing four independent biological replicates.

\section{Confocal microscopy}

Uptake of unlabeled AuNPs in cells was tracked by confocal microscope using two-photon luminescence of AuNPs. HeLa and U937 cells were incubated with AuNPs at a final concentration of $100 \mathrm{pM}$ for $24 \mathrm{~h}$ at $37{ }^{\circ} \mathrm{C}$ in $5 \% \mathrm{CO}_{2}$. The following day, cell culture medium was removed from the cells and replaced by standard complete medium. After $24 \mathrm{~h}$ of incubation, samples were washed with PBS pH 7.4 (Sigma), harvested, and then fixed in buffered $3.7 \%$ formaldehyde (Sigma) for $20 \mathrm{~min}$, permeabilized with $0.1 \%$ 
Triton X-100 (Sigma) in PBS for 5 min, and blocked in PBS, $1 \%$ BSA, and $0.01 \%$ sodium azide for $15 \mathrm{~min}$. Subsequently, cells were incubated with $1 \mathrm{ng} / \mathrm{mL}$ Hoechst 33258 (Sigma) in PBS for nuclei staining, $1 \mu \mathrm{g} / \mathrm{mL}$ Alexa Fluor 488 phalloidin (Molecular Probes) for F-actin staining. After washing, samples were mounted with Fluoromount (Sigma) on glass coverslips to be imaged by confocal microscopy (Leica TCS SP5 AOBS). AuNPs uptaken by cells were imaged by means of the same microscope equipped with a femtosecond Ti:sapphire laser (Mai Tai, Spectra Physics, Newport). Sub-100-fs pulses of $800 \mathrm{~nm}$ light were used as the excitation source, while AuNPs two-photon luminescence was collected between 450 and $600 \mathrm{~nm}$. The reproducibility of the results was guaranteed by performing four independent biological replicates.

\section{In vitro TUNEL assay}

HeLa and U937 cells, exposed to $15 \mathrm{~nm}$ AuNPs for $48 \mathrm{~h}$, were fixed and stained by using Click-iT TUNEL imaging assay (Molecular Probes) as per manufacturer's instructions. With this technique, it is possible to highlight DNA nicks; detection is based on a click reaction between EdUTP and an azide modified AlexaFluor 647. To provide a positive control, DNase I was used to generate strand breaks in the DNA (100\% TUNEL positive nuclei). Cells were finally counterstained with Hoechst 33342. Samples were imaged by confocal microscopy. TUNEL positive nuclei were stained both with Alexa647 and Hoechst 33342, TUNEL negative nuclei only with Hoechst 33342.

\section{Apoptosis/necrosis assay}

HeLa and U937 cells were cultured in $3.5 \mathrm{~cm}$ glass bottom Petri dishes at density of $10^{5}$ cells $/ \mathrm{mL}$ and exposed to different amounts of $15 \mathrm{~nm}$ AuNPs dispersed in cell culture medium. After $24 \mathrm{~h}$ of incubation, citrate-capped AuNPs stock suspension were added in the single dishes obtaining final AuNPs concentrations of 1, 10, 100, and $500 \mathrm{pM}$. AnnexinVFITC apoptosis kit (APOAF Sigma) was used for a direct count of apoptotic and necrotic cells. By this test it is possible to distinguish and count apoptotic cells (AnnexinV+/PI-) and late apoptotic/necrotic cells (AnnexinV+/PI+). After 48 and $96 \mathrm{~h}$ of incubation, samples were washed in $1 \times$ binding buffer, incubated in the dark with AnnexinV-FITC and propidium iodide (PI), as described in the manufacturer's instructions. For both cell lines, a final concentration of $1 \mu \mathrm{g} / \mathrm{mL}$ staurosporine (Sigma) was used as positive control that gave an increase of $60-65 \%$ of apoptotic cells and 20-25\% necrotic cells with respect to the untreated cells (data not shown in the graphs). For apoptotic/necrotic cells counting, we acquired 10 random fields for each sample by a confocal microscope (Leica TCS SP5 AOBS). Samples were observed through a $20 \times, 0.70 \mathrm{NA}$ objective. For statistical analysis and reproducibility verification, each experiment was performed with four biological replicates. Data were expressed as mean $\pm \mathrm{SD}$.

\section{ICP analyses}

To quantify the amount of internalized Au per cell, we used elemental analysis by inductively coupled plasma atomic emission spectroscopy (ICP-AES, Varian Vista AX spectrometer). HeLa and U937 cells were seeded in six-well plates (Sarsted) at density $10^{6}$ cells $/ \mathrm{mL}$. Cells were treated for 48 and $96 \mathrm{~h}$ with 500 pM citrate-capped AuNPs. Untreated cells were used as control. Five replicates were analyzed for each treatment. After incubation, adherent HeLa cells were detached by trypsinization and both cell lines were washed twice by centrifugation in sterile PBS. The number of cells was determined by a hemocytometer and cell suspensions were standardized at $10^{6}$ cell/ $\mathrm{mL}$. Samples were dissolved overnight in $1 \mathrm{~mL}$ of concentrated $\mathrm{HCl} / \mathrm{HNO}_{3} 3: 1(\mathrm{v} / \mathrm{v})$, diluted to $10 \mathrm{~mL}$ with ultrapure water, and the resulting solution directly analyzed by ICP.

In vivo assays

\section{Drosophila melanogaster strain and culture conditions}

The flies and larvae of wild-type D. melanogaster (Oregon $\mathrm{R}+$ ) were cultured at $24 \pm 1{ }^{\circ} \mathrm{C}$ on standard Drosophila food, containing agar, corn meal, sugar, yeast, and nepagin (methyl-p-hydroxybenzoate).

\section{AuNPs treatment}

For toxicity assays, citrate-capped AuNPs were formulated in the diet. Two different concentrations 
(100 and $900 \mathrm{pM}$ ) of AuNPs dispersed in the food were used for experiments (the $100 \mathrm{pM}$ concentration of AuNPs corresponds to $10.34 \mu \mathrm{M}$ or $2.03 \mu \mathrm{g} / \mathrm{mL}$ of $\mathrm{Au}$, or $6.02 \times 10^{10} \mathrm{NPs} / \mathrm{mL}$, or $4.22 \times 10^{-5} \mathrm{~m}^{2} / \mathrm{mL}$ ). In particular, the suspension containing AuNPs was added to the food before solidification, mixed strongly and finally poured into vials. TEM analyses showed that the AuNPs do not significantly aggregate after mixing with the Drosophila food, maintaining a good degree of monodispersity (Fig. S1). With the same modality, we prepared food with AuNPs SN, obtained by centrifugation of NPs suspension at 13,400 rpm for $30 \mathrm{~min}$. This preparation was used to exclude the presence of toxic compounds in the suspension containing AuNPs. Taking into account that each Drosophila ingests, on average, a volume of $1.50 \pm$ $0.04 \mu \mathrm{L}$ of food per day (Ja et al. 2007), the two AuNPs concentrations of 100 and $900 \mathrm{pM}$ correspond to ca. 3 and $27 \mu \mathrm{g} / \mathrm{g}$ per day, respectively.

\section{Lifespan experiments}

For longevity analyses, flies were maintained in vials in groups of 20, transferred into new vials every 4 days, and counted daily until died. We performed five independent experiments, using 200 just eclosed flies for each experiment. In particular, we carried out this experiment using normal food, treated food containing AuNPs SN and treated food containing 100 and 900 pM AuNPs.

\section{Fertility and reproductive performance}

The method of Gayathri and Krishnamurthy (1981) was followed with some modifications. Virgin flies emerging from control, two AuNPs-treated food (with 100 and $900 \mathrm{pM}$ AuNPs) and SN were isolated and pair mated in normal food vials. Pair mating was conducted in two different conditions per treatment group (30 pairs of flies were taken per each treatment group): (1) treated males with normal females and (2) normal males with treated females. Flies were transferred into fresh vials every day for the subsequent 10 days. The total number of flies eclosed from the eggs laid during these 10 days of pair mating was counted. The mean number of flies emerged per pair for 10 days gave a measure of the reproductive performance.

\section{ROS measurement}

The intracellular ROS level in Drosophila was measured using non-fluorescent 2,7-dichlorofluoresceindiacetate (DCF-DA, Molecular Probes, Eugene, OR), a cell permeable dye that can be converted into 2,7dichlorofluoroscein (DCF) on interaction with hydrogen peroxide (Ischiropoulos et al. 1999). Briefly, 20 five-day-old flies were homogenized in tubes containing $1 \mathrm{~mL}$ PBST (PBS containing 0.1\% Tween-20). The SN of each sample was divided in two different vials: the first vial was transferred into a 96-well plate. After adding $50 \mu \mathrm{M}$ DCF-DA to the samples, the plate was read every $5 \mathrm{~min}$ for $15 \mathrm{~min}$ with a fluorescent microplate reader (FLUO Star Optima, BMG Laboratory, Offenberg, Germany) for the quantification of fluorescence $(485 \mathrm{~nm}$ excitation and $520 \mathrm{~nm}$ emission). The second vial was used for protein crude extract quantification. Following centrifugation at 2,300 $\mathrm{g}$ for $15 \mathrm{~min}$ at $4{ }^{\circ} \mathrm{C}$ in the presence of a protease inhibitor, the $\mathrm{SN}$ was quantified by the Bradford method (Bradford 1976). The amount of proteins in the crude extraction was used to normalize the relative fluorescence measured by DCFH-DA in each sample. Three independent experiments with 20 flies in each experiment were performed.

\section{In vivo Comet assay}

Drosophila melanogaster hemocytes were collected according to Irving et al. (2005) with minor modifications. Chilled larvae $96 \pm 2 \mathrm{~h}$ old were removed from food media, washed in water, sterilized in 5\% bleach, and dried. The cuticle from 30 to 40 larvae was then disrupted with two fine forceps. The hemolymph and circulating hemocytes were collected in cold PBS solution containing $0.07 \%$ PTU and separated in $1.5 \mathrm{~mL}$ microcentrifuge tubes. According to Braun et al. (1998), the number of hematocytes per larvae ranges from 1,000 to 1,500 . Pooled hemolymph was centrifuged at $300 \mathrm{~g}$ for $10 \mathrm{~min}$ at $4{ }^{\circ} \mathrm{C}$, the $\mathrm{SN}$ was discarded, and the pellet was re-suspended in $20 \mu \mathrm{L}$ of cold PBS. The Comet assay was performed as previously described by Singh et al. (1988) with minor modifications. Cell samples $(\sim 40,000$ cells in $20 \mu \mathrm{L}$ ) were carefully re-suspended in $75 \mu \mathrm{L}$ of $0.75 \%$ low melting agarose (LMA) and then layered onto microscope slides precoated with $1 \%$ normal 
melting agarose (NMA) and dried at room temperature. Two gels were mounted on each slide and covered with a coverslip. Immediately, after agarose solidification (for $10 \mathrm{~min}$ at $4{ }^{\circ} \mathrm{C}$ ), the coverslips were removed, and the slides were immersed in a cold fresh lysis solution (2.5 M NaCl, $100 \mathrm{mM}$ EDTA, $10 \mathrm{mM}$ Tris, $1 \%$ Triton $\mathrm{X}-100$, and $10 \%$ DMSO, $\mathrm{pH} 10$ ) for $2 \mathrm{~h}$ at $4{ }^{\circ} \mathrm{C}$ in a dark chamber. To prevent additional DNA damage, the following steps were performed under dim light. The slides were placed for $20 \mathrm{~min}$ in a horizontal gel electrophoresis tank filled with cold electrophoretic buffer $(1 \mathrm{mM}$ EDTA and $300 \mathrm{mM}$ $\mathrm{NaOH}, \mathrm{pH}$ 13) to allow for DNA unwinding. The electrophoresis was carried out in the same buffer for $25 \mathrm{~min}$ at $25 \mathrm{~V}$ and $300 \mathrm{~mA}(0.73 \mathrm{~V} / \mathrm{cm})$. Unwinding and electrophoresis processes were accomplished at $4{ }^{\circ} \mathrm{C}$. After electrophoresis, slides were neutralized with two washes of $5 \mathrm{~min}$ with $0.4 \mathrm{mM}$ Tris ( $\mathrm{pH} 7.5$ ). The slides were stained with $20 \mu \mathrm{L}$ of DAPI $(1 \mu \mathrm{g} /$ $\mathrm{mL})$ per gel. One hundred randomly selected cells (50 cells per two replicate slides) were analyzed per treatment.

\section{Gene expression level by real-time qPCR}

Third instar larvae extracts were prepared by homogenizing larvae in groups of 10 in cold solution of RNAlater (Sigma). Hsp70 and p53 mRNA expression levels were examined by performing real-time quantitative reverse transcription PCR in larvae nurtured with food containing $100 \mathrm{pM}$ AuNPs and larvae nurtured with normal food. Total RNA was isolated from flies using Tri-reagent (Sigma), the amount of RNA in each sample was determined by Nanodrop, and RNA quality was analyzed using agarose gel electrophoresis (1.2\%). Real-time PCR was performed using direct RNAs in one-step reaction in a ABI 7500 thermocycler (Applied Biosystems). For each gene, we used $1 \mu \mathrm{L}$ of $0.5 \mu \mathrm{g} / \mu \mathrm{L}$ of RNA solution mixed with $10 \mu \mathrm{L}$ of $10 \times$ Express Syber Green qPCR SuperMix premixed with ROX (Invitrogen), $2 \mu \mathrm{L}$ of $4 \mu \mathrm{M}$ gene specific primers mix, $0.5 \mu \mathrm{L}$ of Express SuperScript Mix for one-Step Syber GreenER (Invitrogen), and $6.5 \mu \mathrm{L}$ of DEPC-treated water. Reaction conditions for all genes were $50{ }^{\circ} \mathrm{C}$ for $5 \mathrm{~min}$ to perform cDNA synthesis and then immediately followed by PCR quantification program, repeated 40 times $\left(15 \mathrm{~s}\right.$ at $95{ }^{\circ} \mathrm{C}, 1 \mathrm{~min}$ at $\left.60{ }^{\circ} \mathrm{C}\right)$. This program was followed by a melting curve program $\left(60-99{ }^{\circ} \mathrm{C}\right.$ with a heating rate of $0.1{ }^{\circ} \mathrm{C} / \mathrm{s}$ and continuous fluorescence measurements). Relative expression was calculated from cycle threshold values $\left(\Delta \Delta C_{\mathrm{t}}\right.$ method) using the ribosomal protein L32 (RpL32) expression as internal control for each sample.

The primers used in real-time qPCR analysis were designed by online Primer-BLAST software of NCBI. In particular, Rpl32 primer (forward: CGA GTT GAA CTG CCT TCA AGA TGA CCA and reverse: CCG ACT GGT GGC GGA TGA AGT G) that amplify the target sequence NM_001144656.1, hsp70 primer (forward: AGG GTC AGA TCC ACG ACA TC and reverse: CGT CTG GGT TGA TGG ATA GG) that amplify the target sequences NM_176486.1; NM_ 169469.1; NM_169441.1; NM_141952.1; NM_080188.2; NM_080059.2, and p53 primer (forward: TGC GGA CAC AAA TCG CAA CTG CT and reverse: ACG ACG CGG ACT TGT GAA GAC TC) that amplify the target sequences NM_001170223.1; NM_206544.2. All the target sequences are reported as NCBI accession number.

\section{Statistical analyses}

GraphPad Prism 5 statistical analyses software was used in all statistical analyses performed in this study (GraphPad Prism version 5.00 for Windows, GraphPad Software, San Diego, CA). In particular, regarding experiments with Drosophila, the survival distributions (lifespan curves) were assessed in terms of significance using the non-parametric log-rank (Mantel-Cox) test and the $\tau_{50}$ data by one-way ANOVA, while real-time qPCR results were analyzed by twoway ANOVA, and all gene expression was compared to the control by Bonferroni post-test. In all the other in vitro and in vivo assays, data were analyzed by one-way ANOVA and compared to the control by Bonferroni post-test. Differences between treated samples and controls were considered statistically significant for $p$ value $<0.001(* * *), p$ value $<0.01(* *), p$ value $<0.05\left(^{*}\right)$, and non-significant for $p$ value $>0.05$ (ns).

Acknowledgments The authors gratefully acknowledge M.A. Malvindi for help during experiments and V. Fiorelli for the expert technical assistance. 


\section{References}

Ahamed M, Posgai R, Gorey TJ, Nielsen M, Hussain SM, Rowe JJ (2010) Silver nanoparticles induced heat shock protein 70 , oxidative stress and apoptosis in Drosophila melanogaster. Toxicol Appl Pharmacol 242(3):263-269

Barnes CA, Elsaesser A, Arkusz J, Smok A, Palus J, Leśniak A, Salvati A, Hanrahan JP, Jong WH, Dziubałtowska E, Stępnik M, Rydzyński K, McKerr G, Lynch I, Dawson KA, Howard CV (2008) Reproducible Comet assay of amorphous silica nanoparticles detects no genotoxicity. Nano Lett 8(9):3069-3074

Bhabra G, Sood A, Fisher B, Cartwright L, Saunders M, Evans WH, Surprenant A, Lopez-Castejon G, Mann S, Davis SA, Hails LA, Ingham E, Verkade P, Lane J, Heesom K, Newson R, Case CP (2009) Nanoparticles can cause DNA damage across a cellular barrier. Nat Nanotechnol 4(12): 876-883

Bhargav D, Pratap Singh M, Murthy RC, Mathur N, Misra D, Saxena DK, Kar Chowdhuri D (2008) Toxic potential of municipal solid waste leachates in transgenic Drosophila melanogaster (hsp70-lacZ): hsp70 as a marker of cellular damage. Ecotox Environ Saf 69(2):233-245

Botas J (2007) Drosophila researchers focus on human disease. Nat Genet 39(5):589-591

Bradford MM (1976) A rapid and sensitive method for the quantitation of microgram quantities of protein utilizing the principle of protein-dye binding. Anal Biochem 72:248-254

Brandenberger C, Rothen-Rutishauser B, Muhlfeld C, Schmid O, Ferron GA, Maier KL, Gehr P, Lenz AG (2010) Effects and uptake of gold nanoparticles deposited at the air-liquid interface of a human epithelial airway model. Toxicol Appl Pharm 242(1):56-65

Braun A, Hoffmann JA, Meister M (1998) Analysis of the Drosophila host defense in domino mutant larvae, which are devoid of hemocytes. Proc Natl Acad Sci USA 95(24):14337-14342

Carmona ER, Guecheva TN, Creus A, Marcos R (2011) Proposal of an in vivo comet assay using haemocytes of Drosophila melanogaster. Environ Mol Mutagen 52(2):165-169

Cedervall T, Lynch I, Lindman S, Berggård T, Thulin E, Nilsson H, Dawson KA, Linse S (2007) Understanding the nanoparticle-protein corona using methods to quantify exchange rates and affinities of proteins for nanoparticles. Proc Natl Acad Sci USA 104(7):2050-2055

Chompoosor A, Saha K, Ghosh PS, Macarthy DJ, Miranda OR, Zhu ZJ, Arcaro KF, Rotello VM (2010) The role of surface functionality on acute cytotoxicity, ROS generation and DNA damage by cationic gold nanoparticles. Small 6(20): 2246-2249

Connor EE, Mwamuka J, Gole A, Murphy CJ, Wyatt MD (2005) Gold nanoparticles are taken up by human cells but do not cause acute cytotoxicity. Small 1(3):325-327

Deng ZJ, Liang M, Monteiro M, Toth I, Minchin RF (2011) Nanoparticle-induced unfolding of fibrinogen promotes Mac-1 receptor activation and inflammation. Nat Nanotechnol 6(1):39-44

Downey GP, Doherty DE, Schwab B, Elson EL, Henson PM, Worthen GS (1990) Retention of leukocytes in capillaries: role of cell size and deformability. J Appl Physiol 69(5): $1767-1778$

Eck W, Nicholson AI, Zentgraf H, Semmler W, Sn Bartling (2010) Anti-CD4-targeted gold nanoparticles induce specific contrast enhancement of peripheral lymph nodes in $\mathrm{X}$-ray computed tomography of live mice. Nano Lett 10(7):2318-2322

El-Sayed IH, Huang X, El-Sayed MA (2005) Surface plasmon resonance scattering and absorption of anti-EGFR antibody conjugated gold nanoparticles in cancer diagnostics: applications in oral cancer. Nano Lett 5(5):829-834

Farrer RA, Butterfield FL, Chen VW, Fourkas JT (2005) Highly efficient multiphoton-absorption-induced luminescence from gold nanoparticles. Nano Lett 5(6):1139-1142

Frens G (1973) Controlled nucleation for the regulation of the particle size in monodisperse gold suspensions. Nat Phys Sci 241(105):20-22

Gannon CJ, Patra CR, Bhattacharya R, Mukherjee P, Curley SA (2008) Intracellular gold nanoparticles enhance non-invasive radiofrequency thermal destruction of human gastrointestinal cancer cells. J Nanobiotechnol 6:2

Gayathri MV, Krishnamurthy NB (1981) Studies on the toxicity of the mercurial fungicide Agallol 3 in Drosophila melanogaster. Environ Res 24(1):89-95

Gibson JD, Khanal BP, Zubarev ER (2007) Paclitaxel-functionalized gold nanoparticles. J Am Chem Soc 129(37): 11653-11661

Irving P, Ubeda J-M, Doucet D, Troxler L, Lagueux M, Zachary D, Hoffmann JA, Hetru C, Meister M (2005) New insights into Drosophila larval haemocyte functions through genome-wide analysis. Cell Microbiol 7(3):335-350

Ischiropoulos H, Gow A, Thom SR, Kooy NW, Royall JA, Crow JP (1999) [38] Detection of reactive nitrogen species using 2,7-dichlorodihydrfluorescein and dihydrorhodamine 123 . Methods Enzymol 301:367-373

Ja WW, Carvalho GB, Mak EM, de la Rosa NN, Fang AY, Liong JC, Brummel T, Benzer S (2007) Prandiology of Drosophila and the CAFE assay. Proc Natl Acad Sci USA 104(20):8253-8256

Jan E, Byrne SJ, Cuddihy M, Davies AM, Volkov Y, Gun'ko YK, Kotov NA (2008) High-content screening as a universal tool for fingerprinting of cytotoxicity of nanoparticles. ACS Nano 2(5):928-938

Jennings BH (2011) Drosophila - a versatile model in biology and medicine. Mater Today 14(5):190-195

Khan JA, Pillai B, Das TK, Singh Y, Maiti S (2007) Molecular effects of uptake of gold nanoparticles in HeLa cells. Chembiochem 8(11):1237-1240

Krug HF, Wick P (2011) Nanotoxicology: an interdisciplinary challenge. Angew Chem Int Ed 50(6):1260-1278

Lee J-S, Stoeva SI, Mirkin CA (2006) DNA-induced sizeselective separation of mixtures of gold nanoparticles. J Am Chem Soc 128(27):8899-8903

Li JJ, Zou L, Hartono D, Ong CN, Bay BH, Yung LYL (2008) Gold nanoparticles induce oxidative damage in lung fibroblasts in vitro. Adv Mater 20(1):138-142

Li JJ, Hartono D, Ong CN, Bay BH, Yung LY (2010) Autophagy and oxidative stress associated with gold nanoparticles. Biomaterials 31(23):5996-6003 
Lieschke GJ, Currie PD (2007) Animal models of human disease: zebrafish swim into view. Nat Rev Genet 8(5): 353-367

Lin W, Huang Y-w, Zhou X-D, Ma Y (2006) In vitro toxicity of silica nanoparticles in human lung cancer cells. Toxicol Appl Pharm 217(3):252-259

Liu X, Vinson D, Abt D, Hurt RH, Rand DM (2009) Differential toxicity of carbon nanomaterials in Drosophila: larval dietary uptake is benign, but adult exposure causes locomotor impairment and mortality. Environ Sci Technol 43(16):6357-6363

Lledías F, Hansberg W (1999) Oxidation of human catalase by singlet oxygen in myeloid leukemia cells. Photochem Photobiol 70(6):887-892

Lundqvist M, Stigler J, Elia G, Lynch I, Cedervall T, Dawson KA (2008) Nanoparticle size and surface properties determine the protein corona with possible implications for biological impacts. Proc Natl Acad Sci USA 105(38): $14265-14270$

Maiorano G, Sabella S, Sorce B, Brunetti V, Malvindi MA, Cingolani R, Pompa PP (2010) Effects of cell culture media on the dynamic formation of protein-nanoparticle complexes and influence on the cellular response. ACS Nano 4(12):7481-7491

Massich MD, Giljohann DA, Schmucker AL, Patel PC, Mirkin CA (2010) Cellular response of polyvalent oligonucleotidegold nanoparticle conjugates. ACS Nano 4(10):5641-5646

OECD Safety of Manufactured Nanomaterials (2010) http:// www.oecd.org/document/53/0,3746,en_2649_37015404_ 37760309_1_1_1_1,00\&\&en-USS_01DBC.html

Pan Y, Leifert A, Ruau D, Neuss S, Bornemann J, Schmid G, Brandau W, Simon U, Jahnen-Dechent W (2009) Gold nanoparticles of diameter $1.4 \mathrm{~nm}$ trigger necrosis by oxidative stress and mitochondrial damage. Small 5(18): 2067-2076

Park MVDZ, Annema W, Salvati A, Lesniak A, Elsaesser A, Barnes C, McKerr G, Howard CV, Lynch I, Dawson KA, Piersma AH, de Jong WH (2009) In vitro developmental toxicity test detects inhibition of stem cell differentiation by silica nanoparticles. Toxicol Appl Pharmacol 240(1): 108-116

Patra HK, Banerjee S, Chaudhuri U, Lahiri P, Dasgupta AK (2007) Cell selective response to gold nanoparticles. Nanomedicine 3(2):111-119

Pernodet N, Fang X, Sun Y, Bakhtina A, Ramakrishnan A, Sokolov J, Ulman A, Rafailovich M (2006) Adverse effects of citrate/gold nanoparticles on human dermal fibroblasts. Small 2(6):766-773

Pompa PP, Vecchio G, Galeone A, Brunetti V, Sabella S, Maiorano G, Falqui A, Bertoni G, Cingolani R (2011a) In vivo toxicity assessment of gold nanoparticles in Drosophila melanogaster. Nano Res 4(4):405-413

Pompa PP, Vecchio G, Galeone A, Brunetti V, Maiorano G, Sabella S, Cingolani R (2011b) Physical assessment of toxicology at nanoscale: nano dose-metrics and toxicity factor. Nanoscale 3(7):2889-2897

Rivera Gil P, Oberdöroster G, Elder A, Puntes V, Parak WJ (2010) Correlating physico-chemical with toxicological properties of nanoparticles: the present and the future. ACS Nano 4(10):5527-5531

Rosi NL, Giljohann DA, Thaxton CS, Lytton-Jean AKR, Han MS, Mirkin CA (2006) Oligonucleotide-modified gold nanoparticles for intracellular gene regulation. Science 312(5776):1027-1030

Sabella S, Galeone A, Vecchio G, Cingolani R, Pompa PP (2011) AuNPs are toxic in vitro and in vivo: a review. J Nanosci Lett 1(3):145-165

Schaeublin NM, Braydich-Stolle LK, Schrand AM, Miller JM, Hutchison J, Schlager JJ, Hussain SM (2011) Surface charge of gold nanoparticles mediates mechanism of toxicity. Nanoscale 3(2):410-420

Shukla R, Bansal V, Chaudhary M, Basu A, Bhonde RR, Sastry M (2005) Biocompatibility of gold nanoparticles and their endocytotic fate inside the cellular compartment: a microscopic overview. Langmuir 21(23):10644-10654

Singh NP, McCoy MT, Tice RR, Schneider EL (1988) A simple technique for quantitation of low levels of DNA damage in individual cells. Exp Cell Res 175(1):184-191

Singh MP, Reddy MMK, Mathur N, Saxena DK, Chowdhuri DK (2009) Induction of hsp70, hsp60, hsp83 and hsp26 and oxidative stress markers in benzene, toluene and xylene exposed Drosophila melanogaster: role of ROS generation. Toxicol Appl Pharmacol 235(2):226-243

Somasundaram K (2000) Tumor suppressor p53: regulation and function. Front Biosci 5:D424-D437

Turkevich J, Stevenson PC, Hillier J (1951) A study of the nucleation and growth processes in the synthesis of colloidal gold. Discuss Faraday Soc 11:55-75

Warheit DB (2008) How meaningful are the results of nanotoxicity studies in the absence of adequate material characterization? Toxicol Sci 101(2):183-185

Yamamoto T, Sakaguchi N, Hachiya M, Nakayama F, Yamakawa M, Akashi M (2008) Role of catalase in monocytic differentiation of U937 cells by TPA: hydrogen peroxide as a second messenger. Leukemia 23(4):761-769

Yang J, Tower J (2009) Expression of hsp22 and hsp70 transgenes is partially predictive of Drosophila survival under normal and stress conditions. J Gerontol Ser A 64A(8):828-838

Yelin D, Oron D, Thiberge S, Moses E, Silberberg Y (2003) Multiphoton plasmon-resonance microscopy. Opt Express 11(12):1385-1391

Zhao L, Kroenke CD, Song J, Piwnica-Worms D, Ackerman JJH, Neil JJ (2008) Intracellular water-specific MR of microbead-adherent cells: the HeLa cell intracellular water exchange lifetime. NMR Biomed 21(2):159-164

Zylicz M, King FW, Wawrzynow A (2001) Hsp70 interactions with the p53 tumour suppressor protein. EMBO J 20(17): 4634-4638 